\title{
Desenvolvimento da linguagem em crianças surdas: uma revisão integrativa
}

\section{Language development in deaf children's: an integrative review}

\section{Desarrollo del lenguaje en niños sordos: una revisión integradora}

Recebido: 10/06/2013

Aprovado: 25/10/2013

\author{
Nathália Fernandes Minaré ${ }^{1}$ \\ Fabio Scorsolini-Comin ${ }^{2}$ \\ Manoel Antônio dos Santos ${ }^{3}$
}

No contexto das deficiências auditivas, a linguagem é considerada crucial para o pleno desenvolvimento da criança. 0 objetivo deste artigo é revisar a literatura científica nacional acerca da linguagem e de seu desenvolvimento em crianças surdas. Foram utilizados os descritores "linguagem" e "surdez", nas bases de dados LILACS, SciELO e PePSIC, no período 2000-2011. Os 10 artigos levantados abordavam a linguagem no contexto da surdez, especificamente em relação às categorias: educação, identidade, linguagem escrita, simbolismo e família. A categoria do simbolismo nas linguagens do surdo foi a que mais se destacou, pois é a que melhor explica o processo de desenvolvimento da linguagem. Todos os eixos analíticos remetem a ela, contudo, poucos estudos a abordam, o que dificulta a elucidação das especificidades do contexto da surdez. Além disso, embora discorram sobre a linguagem, poucos analisam seu desenvolvimento - e, nesse aspecto, a função simbólica é essencial. Propõem-se mais estudos sobre o tema, a fim de eliminar preconceitos.

Descritores:Linguagem; Surdez; Desenvolvimento da linguagem.

In the context of auditory deficiencies, hearing, the language is considered crucial for full development of child. The aim of this paper is to review the scientific literature about the national language and its development in deaf children. It is used the keywords "language" and "deafness" in the databases LILACS, SciELO and PePSIC in the period 2000-2011. 10 articles retrieved were related to the language in the context of deafness, specifically in relation to the categories of education, identity, written language, symbolism and family. The category of symbolism in the language of the deaf was the one that stood out because it best explains the process of language development. All analytical axes refer to it, however, few studies address, making it difficult to elucidate the specific context of deafness. In addition, although talked about the language, few analyze their development - and in that respect, the symbolic function is essential. It is propose further studies on the subject, in order to eliminate prejudices.

Descriptors:Language; Deafness; Language development.

En el contexto de las deficiencias auditivas, audición, el lenguaje es crucial para el desarrollo pleno del niño. El propósito de este artículo es revisar la literatura científica nacional sobre la lenguaje y su desarrollo en niños sordos. Se utilizó el término "lenguaje" y "sordera" en las bases de datos LILACS, SciELO y PePSIC en el período de 2000-2011. Los diez artículos levantados se dirigieron a la lengua en el contexto de la sordera, específicamente en relación con las categorías: educación, identidad, lenguaje escrito, simbolismo y familia. La categoría simbolismo en las lenguas de los sordos fue el que se destacó por ser lo que mejor explica el proceso de desarrollo del lenguaje. Todos los ejes de análisis se refieren a ella, sin embargo, son pocos los estudios en esta dirección, por lo que es difícil de dilucidar el contexto específico de la sordera. Por otra parte, aunque discurran en el lenguaje, pocos analizan su desarrollo - y en este sentido, la función simbólica es esencial. Propone-se realizar más estudios sobre el tema, con el fin de eliminar los preconceptos.

Descriptores:Lenguaje; Sordera; Desarrollo del lenguaje.

1. Graduanda do curso de Psicologia da Universidade Federal do Triângulo Mineiro (UFTM). Email: nathminare@hotmail.com 2. Professor Adjunto do Departamento de Psicologia da UFTM. Doutor em Psicologia. Líder do PROSA - Laboratório de Investigações sobre Práticas Dialógicas e Relacionamentos Interpessoais (CNPq). Pesquisador do Laboratório de Ensino e Pesquisa em Psicologia da Saúde (LEPPS-USP-CNPq). Email: scorsolini_usp@yahoo.com.br

3. Professor Associado do Departamento de Psicologia da Faculdade de Filosofia, Ciências e Letras de Ribeirão Preto da Universidade de São Paulo. Líder do Laboratório de Ensino e Pesquisa em Psicologia da Saúde (LEPPS-USP-CNPq). Bolsista de Produtividade em Pesquisa do CNPq. Email: masantos@ffclrp.usp.br 


\section{INTRODUÇÃo}

$\mathrm{N}$ o início do detalhado estudo sobre surdez realizado pelo neurologista Oliver Sacks ${ }^{1}$, é evidenciada a relação entre linguagem e pensamento como a mais importante questão a ser considerada na convivência com pessoas surdas e no estudo de sua condição. Uma das bases comprobatórias de tal afirmação é a teoria interacionista de $V_{y g o t s k y}{ }^{2}$, que explica a estreita relação do pensamento com a linguagem.

Considerando esse pressuposto, pode-se deduzir a magnitude da importância do desenvolvimento da linguagem na criança, um processo que, inevitavelmente, acarreta tanto mudanças estruturais quanto psicológicas $^{3,4}$. Em tempos anteriores, porém, a palavra era vista como manifestação externa simultânea ao pensamento, sem influenciar a vida interior $^{2}$. Contrariando esse ponto de vista, Vygotsky defende a existência de uma real interdependência entre pensamento e palavra: a relação é um processo contínuo, no qual tanto a linguagem como o pensamento sofrem transformações funcionais ${ }^{2}$. Desse modo, adquirir domínio de uma língua própria, a qual o indivíduo entenda o suficiente para conseguir aplicá-la em seu cotidiano, favorece seu ato de pensar e, consequentemente, de compreender o mundo e de se relacionar com ele 5 .

Um tema desafiador no campo das deficiências, mas que, na verdade, é de interesse da área mais ampla do conhecimento, remete à compreensão de como se dá o processo de aquisição da linguagem na criança portadora de grave deficiência auditiva. Retornando a Sacks' ${ }^{1}$, é essencial atentar para a capacidade linguística do surdo, a fim de que este possa, apesar de sua condição, desenvolver plenas habilidades de pensamento, raciocínio e socialização. A língua de sinais - descrita como uma língua cujo meio são sinais feitos com mãos e cabeça - é a linguagem ideal para propiciar desenvolvimento e identificação surda. Afinal, embora a fala seja o meio mais conhecido de uma língua, ela não é o único recurso possível ${ }^{6}$. Diversos preconceitos e recriminações em relação à população surda poderiam ter sido evitados se essa ideia prevalecesse em $1750^{1}$.

Os obstáculos interpostos entre as várias vantagens humanas, além da fala, despertaram, entretanto, o interesse e as filosofias de estudiosos da época. Baseadas em pensamentos mais racionalizados $\mathrm{e}$ destituídos de "pré-conceitos" pejorativos, novas concepções da surdez puderam aflorar. Afinal, reconheceu-se que a constituição biológica geral dos surdos não era tão diferente da dos demais - logo, eles não deveriam estar impedidos de possibilidades das quais os ouvintes usufruíam. A resposta para a sua comunicação era lógica: os sinais, os gestos ${ }^{1}$. Estes, contudo, não são exclusivos dos surdos - qualquer pessoa os utiliza em sua comunicação rotineira, principalmente quando necessita de dar mais ênfase para se fazer entender. A língua de sinais emerge espontaneamente quando um grupo de pessoas surdas vive junto ou é colocado em um mesmo ambiente ${ }^{6}$. Elas criam uma linguagem própria, gesto-visual e intrincada ${ }^{7}$, que utiliza tanto o hemisfério cerebral esquerdo (responsável pelo processamento visual e espacial) quanto o direito (característico da linguagem).

A ilustração de Sacks ${ }^{1}$ sobre a ilha de Martha'sVineyard, na qual uma surdez hereditária durou por 250 anos e tornou quase todos os habitantes surdos-mudos, retrata muito bem o status da língua de sinais e suas implicações na formação do pensamento. 0 autor destaca que o uso contínuo dos sinais era tão forte que, mesmo após a morte do último ilhéu surdo, os demais (ouvintes), preservaram os sinais entre si de modo geral, involuntário e natural, "porque a língua de sinais é 'natural' para todos que a aprendem (como primeira língua), e possui beleza e excelência intrínsecas, às vezes superiores às da fala"1.

0 relato do neurologista sobre sua visita à ilha traz o exemplo de uma senhora que, por vezes, parecia devanear, sozinha, e suas mãos pareciam realizar um "tricô 
invisível"; contudo, segundo sua filha, ela estava conversando consigo mesma na língua de sinais, pensando apenas. "E mesmo dormindo (...), aquela senhora às vezes esboçava sinais fragmentários nas cobertas - estava sonhando na língua de sinais"1. É lógica, portanto, a afirmação do autor de que a língua de sinais é uma "língua fundamental do cérebro", capaz de mediar pensamentos e interações sociais e até personalidades. Nessa direção, é aplicável a teoria de Vygotsky², que afirma o pensamento como interdependente e também constituído pela linguagem, em um meio sociocultural que permite a inclusão do indivíduo diferente ou não. É necessário o conhecimento do surdo sobre si e de toda a população sobre a realidade da surdez e, primordialmente, sobre como se dá o desenvolvimento da linguagem em tal contexto.

Com base nesse panorama, este estudo tem por objetivo revisar a literatura científica nacional acerca da linguagem e de seu desenvolvimento em crianças surdas.

\section{MÉTODO}

Tipo de estudo: para alcançar o objetivo proposto, escolheu-se a modalidade de trata-se de uma revisão integrativa. Esse tipo de revisão da literatura científica permite organizar a literatura para compartilhar resultados e informações de demais estudos com os leitores, de modo abrangente e crítico, além de relacionar os estudos disponíveis com a área de investigação, estabelecendo diálogos que proporcionem preencher lacunas e promover comparações ${ }^{8}$.

Critérios de inclusão/exclusão: Foram considerados apenas artigos científicos publicados em periódicos indexados, disponíveis na língua portuguesa, no período entre 2000 a 2011, cujos temas abordavam primordialmente a questão da linguagem (seja a língua de sinais ou a língua portuguesa, oral ou escrita) e seu desenvolvimento em crianças surdas. Foram incorporados artigos teóricos, empíricos e estudos de caso. Além disso, a fim de realizar seleção mais acurada e melhor releitura crítica dos artigos, foram utilizados alguns critérios de exclusão, como o descarte de teses de mestrado ou doutorado, livros, capítulos de livros ou resenhas. Publicações em línguas estrangeiras, distantes do tema definido ou da área da Psicologia, foram igualmente desconsideradas, tais como pesquisas referentes a adultos surdos, ou investigações focadas nas aplicações da Fonoaudiologia.

Bases indexadoras: fForam realizadas buscas nas bases bibliográficas de abrangência nacional e latino-americana: LILACS (Literatura Latino-Americana e do Caribe em Ciências da Saúde), SciELO (Scientific Eletronic Library Online) e PePSIC (Periódicos Eletrônicos de Psicologia). Bases essas disponibilizadas na Rede BVS (Biblioteca Virtual de Saúde) ou BVS-Psi (Biblioteca Virtual de Saúde e Psicologia), e apresentando especificidades distintas que servem de auxílio para deixar a busca por artigos mais completa.

Procedimento: Aas buscas foram realizadas em um único dia, em um computador de uma biblioteca universitária. Foram utilizados os descritores "linguagem" e "surdez" ("surdez para a palavra", de acordo com a Terminologia Psi-Alfabética, mas convertido para "surdez" por todas as bases), juntos, nas três bases de dados. No PePSIC foi utilizado apenas o descritor "surdez", em virtude do baixo número de artigos congruentes com o tema e os critérios de busca obtidos com os dois descritores combinados. Na LILACS, além disso, foi utilizado o dispositivo "documentos relacionados" para encontrar artigos mais semelhantes aos que apresentavam conteúdo pertinente ao tema proposto. A partir daí, foram selecionadas as publicações por meio do título e do tipo de estudo, além dos critérios de inclusão e exclusão supracitados. Os resumos dos artigos foram lidos, a fim de se selecionarem os que seriam recuperados na íntegra para o corpus da revisão.

Análise dos dados: Para a revisão, todos os artigos foram lidos na íntegra. Apesar de apresentarem o mesmo foco, 
afloraram algumas especificidades que não dificultaram a revisão, mas, ao contrário, enriqueceram-na. Por isso, os artigos obtidos foram categorizados de acordo com o "tema", a fim de propiciar melhor aproveitamento de suas informações e, também, de direcionar a análise e discussão dos resultados. São eles: (a) linguagem na educação do surdo, (b) linguagem na construção da identidade surda, (c) linguagem escrita para o surdo, (d) simbolismo nas linguagens do surdo, (e) influências da família no uso da linguagem pelo surdo. Os artigos foram analisados também, segundo seus respectivos objetivos e resultados obtidos.

\section{RESULTADOS}

No total, foram encontrados 64 estudos, sendo 22 na LILACS, 26 na SciELO e 16 no
PePSIC. Posteriormente, com a aplicação dos critérios de inclusão/exclusão, foram selecionados 31 artigos (12 na LILACS, 15 na SciELO e 4 no PePSIC); após análise mais detalhada, 14 artigos foram escolhidos para compor o corpus final da revisão. Contudo, três não puderam ser recuperados, pois seus textos completos não estavam disponíveis na Internet, nem nas bases de dados, tampouco em outros sites da Internet, e um estudo apresentava tema ligeiramente fora do foco da revisão (adulto surdo). Desse modo, foram considerados 10 artigos (cinco na LILACS, quatro na SciELO e um no PePSIC). Os artigos repetidos foram contabilizados apenas uma vez. A Tabela 1 resume as informações que permitem vislumbrar o percurso traçado até a definição do corpus da revisão.

Tabela 1. Bases de dados e número de artigos encontrados, selecionados e considerados. 2000 a 2011.

\begin{tabular}{cccc}
\hline Bases & Encontrados & Selecionados & Considerados \\
\hline LILACS & 22 & 12 & 5 \\
SciELO & 26 & 15 & 4 \\
PePSIC & 16 & 4 & 1 \\
\hline Total & 64 & 31 & 10 \\
\hline
\end{tabular}

Para melhor apreensão dos conteúdos dos artigos considerados, o Quadro 1 resume suas principais características. Pode-se notar a maior presença de estudos empíricos, que se mostraram úteis e importantes por trazerem aplicações práticas e inovadoras em relação ao já estabelecido pela literatura, enquanto os teóricos, embora importantes por suas explicações, não acrescentaram muito à dimensão prática. Já no que concerne aos estudos de caso, percebe-se sua utilidade em investigações com abrangência mais limitada, como é o caso do campo circunscrito pela surdez, além do fato de exporem a necessidade de se mudar tal restrição.

Quadro 1. Identificação dos trabalhos considerados na revisão. 2000 a 2011.

\begin{tabular}{|l|l|l|l|c|}
\hline $\mathbf{N}$ - & \multicolumn{1}{|c|}{ Título } & \multicolumn{1}{|c|}{ Autor/Instituição } & \multicolumn{1}{c|}{ Periódico /Ano } & Tipo de Estudo \\
\hline $\mathbf{1}$ & $\begin{array}{l}\text { O desenvolvimento da linguagem e } \\
\text { a educação do surdo }\end{array}$ & $\begin{array}{l}\text { Rodriguero/ } \\
\text { Universidade Estadual de } \\
\text { Maringá }\end{array}$ & $\begin{array}{l}\text { Psicologia em } \\
\text { Estudo /2000 }\end{array}$ & Teórico \\
\hline $\mathbf{2}$ & $\begin{array}{l}\text { A língua de sinais e a escrita: } \\
\text { possibilidades de se dizer, para o } \\
\text { surdo }\end{array}$ & $\begin{array}{l}\text { Carvalho, Rafaeli / PUC- } \\
\text { SP }\end{array}$ & $\begin{array}{l}\text { Estilos da } \\
\text { Clínica/2003 }\end{array}$ & Estudode caso \\
\hline $\mathbf{3}$ & $\begin{array}{l}\text { A língua de sinais constituindo o } \\
\text { surdo como sujeito }\end{array}$ & $\begin{array}{l}\text { Dizeu, Caporali / } \\
\text { Universidade Federal de } \\
\text { Alagoas, Universidade de } \\
\text { São Paulo }\end{array}$ & $\begin{array}{l}\text { Educação e } \\
\text { Sociedade/2005 }\end{array}$ & Teórico \\
\hline $\mathbf{4}$ & Algumas considerações sobre a & Peixoto / Centro de & Cadernos & Empírico \\
\hline
\end{tabular}




\begin{tabular}{|l|l|l|l|c|}
\hline & $\begin{array}{l}\text { interface entre a Língua Brasileira } \\
\text { de Sinais (LIBRAS) e a Língua } \\
\text { Portuguesa na construção inicial da } \\
\text { escrita pela criança surda }\end{array}$ & $\begin{array}{l}\text { Capacitação de } \\
\text { Profissionais da } \\
\text { Educação e de } \\
\text { Atendimento às Pessoas } \\
\text { com Surdez }\end{array}$ & CEDES/2006 & \\
\hline $\mathbf{5}$ & $\begin{array}{l}\text { Lingua(gem) e identidade: a surdez } \\
\text { em questão }\end{array}$ & $\begin{array}{l}\text { Gesueli / Universidade } \\
\text { Estadual de Campinas }\end{array}$ & $\begin{array}{l}\text { Educação e } \\
\text { Sociedade /2006 }\end{array}$ & Teórico \\
\hline $\mathbf{6}$ & $\begin{array}{l}\text { Mães ouvintes com filhos surdos: } \\
\text { concepção de surdez e escolha da } \\
\text { modalidade de linguagem }\end{array}$ & $\begin{array}{l}\text { Silva, Pereira, Zanolli / } \\
\text { Universidade Estadual de } \\
\text { Campinas }\end{array}$ & $\begin{array}{l}\text { Psicologia: Teoria } \\
\text { e Pesquisa /2007 }\end{array}$ & Empírico \\
\hline $\mathbf{7}$ & $\begin{array}{l}\text { Surdez e linguagem escrita: um } \\
\text { estudo de caso }\end{array}$ & $\begin{array}{l}\text { Guarinello, Massi, } \\
\text { Berberian / Universidade } \\
\text { Tuiuti do Paraná }\end{array}$ & $\begin{array}{l}\text { Revista Brasileira } \\
\text { de Educação } \\
\text { Especial/2007 }\end{array}$ & Estudo de caso \\
\hline $\mathbf{8}$ & $\begin{array}{l}\text { Esferas de atividade simbólica e a } \\
\text { construção de conhecimento pela } \\
\text { criança surda }\end{array}$ & $\begin{array}{l}\text { Araújo, Lacerda / } \\
\text { Universidade Estadual de } \\
\text { Campinas, Universidade } \\
\text { Metodista de Piracicaba }\end{array}$ & $\begin{array}{l}\text { Revista Brasileira } \\
\text { Especial/2008 }\end{array}$ & Empírico \\
\hline $\mathbf{9}$ & $\begin{array}{l}\text { O estatuto simbólico dos gestos no } \\
\text { contexto da surdez }\end{array}$ & $\begin{array}{l}\text { Santana, Guarinello, } \\
\text { Berberian, Massi / } \\
\text { Universidade Tuiuti do } \\
\text { Paraná }\end{array}$ & $\begin{array}{l}\text { Psicologia em } \\
\text { Estudo/2008 }\end{array}$ & Empírico \\
\hline $\mathbf{1 0}$ & $\begin{array}{l}\text { Surdez, mediação e linguagem na } \\
\text { escola }\end{array}$ & $\begin{array}{l}\text { Bniversidade Tuiuti do } \\
\text { Paraná, Universidade } \\
\text { Federal de Santa Maria }\end{array}$ & $\begin{array}{l}\text { Psicologia } \\
\text { USP/2010 }\end{array}$ & Empírico \\
\hline
\end{tabular}

Em relação aos objetivos dos estudos, nota-se que os artigos teóricos (1, 3 e 5) apresentam propostas semelhantes, no sentido de levantar dados e, assim, proporcionar reflexões a respeito do desenvolvimento das linguagens (língua portuguesa e de sinais) na criança surda. Já os artigos empíricos $(4,6,8,9$ e 10) trazem o objetivo apresentado pelos teóricos e também, a comparação entre situações anteriores e posteriores às pesquisas relativas ao desenvolvimento de atividades práticas no cotidiano de seus respectivos sujeitos (como escrita e construção de novos conhecimentos). É válido ressaltar o artigo 6 por fixar um objetivo que não tem como foco diretamente a criança surda, mas sua família (em especial as mães). Também se deve salientar o fato de alguns estudos manifestarem objetivos mais amplos, enquanto outros se restringem a circunscrever especificidades. Quanto aos estudos de caso (2 e 7), há disparidades: enquanto o primeiro propõe um objetivo geral com base em um caso, o segundo deixa claro que visa a analisar apenas o sujeito do estudo em questão, sem advogar a generalização dos achados. $\mathrm{O}$ Quadro 2 visualiza os objetivos. O Quadro 3 contém os principais resultados obtidos por cada estudo.

Quadro 2. Objetivos dos artigos considerados. 2000 a 2011.

\begin{tabular}{|cl|}
\hline $\mathbf{N o}$ & $\begin{array}{l}\text { Levantar dados para reflexão sobre possibilidades de desenvolvimento da linguagem e relação com o desenvolvimento cognitivo e a } \\
\text { educação do surdo }\end{array}$ \\
\hline $\mathbf{2}$ & $\begin{array}{l}\text { Discutir quais processos psíquicos estão envolvidos, a fim de que ocorra o acesso à língua de sinais e à escrita alfabética para o } \\
\text { surdo }\end{array}$ \\
\hline $\mathbf{3}$ & $\begin{array}{l}\text { Discutir aspectos importantes sobre LIBRAS, desenvolvimento de linguagem, cognição e interação sociocultural na formação de } \\
\text { processos identificatórios }\end{array}$ \\
\hline $\mathbf{4}$ & Propor uma reflexão psicolinguística sobre as construções de crianças surdas no que diz respeito à escrita \\
\hline $\mathbf{5}$ & Discutir o papel da língua de sinais na construção da identidade surda, que se faz pela significação \\
\hline $\mathbf{6}$ & $\begin{array}{l}\text { Analisar a concepção que mães ouvintes com filhos surdos têm sobre surdez e relacioná-la com a modalidade de linguagem } \\
\text { utilizada pela mãe e pela criança }\end{array}$ \\
\hline $\mathbf{7}$ & Analisar as produções escritas de um sujeito surdo em momento inicial de apropriação da escrita \\
\hline $\mathbf{8}$ & $\begin{array}{l}\text { Explorar e abordar as esferas simbólicas da linguagem - gesto, desenho, narrativa e escrita - concomitantes à língua de sinais no } \\
\text { desenvolvimento da linguagem da criança surda e na construção de novos conhecimentos }\end{array}$ \\
\hline $\mathbf{9}$ & Discutir a relação entre gesto e língua com base no estudo da surdez e numa perspectiva discursiva da linguagem \\
\hline $\mathbf{1 0}$ & $\begin{array}{l}\text { Analisar a frequência de princípios de mediação e aquisição de linguagem em crianças surdas antes e depois da intervenção com } \\
\text { professoras }\end{array}$ \\
\hline
\end{tabular}


Quadro 3. Resultados dos artigos considerados. 2000 a 2011.

\begin{tabular}{|c|l|}
\hline \multicolumn{1}{|l|}{ No } & \multicolumn{1}{c|}{ Principais Resultados } \\
\hline $\mathbf{1}$ & $\begin{array}{l}\text { O surdo dispõe da condição necessária ao desenvolvimento e aquisição da linguagem; a surdez apenas } \\
\text { impõe possibilidades diferentes à pessoa, e não impossibilita o desenvolvimento dessa condição }\end{array}$ \\
\hline $\mathbf{2}$ & A apropriação da língua de sinais e da escrita trouxe ganhos psíquicos, culturais e sociais para o surdo \\
\hline $\mathbf{3}$ & $\begin{array}{l}\text { Por meio da aquisição da língua de sinais, a criança surda passa a construir sua subjetividade em meio } \\
\text { à identidade surda }\end{array}$ \\
\hline $\mathbf{4}$ & $\begin{array}{l}\text { A escrita nas crianças surdas é diferente da escrita das ouvintes em razão da não fonetização, da } \\
\text { exploração de aspectos visoespaciais e do uso de parâmetros da língua de sinais para regular a escrita }\end{array}$ \\
\hline $\mathbf{6}$ & $\begin{array}{l}\text { A perspectiva da educação bilíngue (sinais e português) antecipa a consciência dos próprios surdos } \\
\text { sobre o significado da surdez, e lhes permite se identificar com uma cultura e enstituir sua } \\
\text { identidade }\end{array}$ \\
\hline $\mathbf{7}$ & $\begin{array}{l}\text { As mães ou veem a surdez como doença, ou como diferença, ou situam-se entre as duas opções, o que } \\
\text { influencia a linguagem usada pela criança. Metade delas diz que os filhos usam sinais, metade utiliza } \\
\text { fala e sinais e uma criança emprega só a linguagem oral }\end{array}$ \\
\hline $\mathbf{8}$ & $\begin{array}{l}\text { O sujeito investigado passou a fazer melhor uso da escrita, com alternâncias e justaposições entre as } \\
\text { duas línguas envolvidas (sinais e português) } \\
\text { consolidando os signos e o desenvolvimento da linguagem }\end{array}$ \\
\hline $\mathbf{9}$ & $\begin{array}{l}\text { Resgate da literatura, que comprova que os estudos evidenciam interdependência de gesto e língua } \\
\text { em termos simbólicos, interativos e cognitivos }\end{array}$ \\
\hline $\mathbf{1 0}$ & $\begin{array}{l}\text { Consequências importantes na comunicação das crianças e mudanças no processo de mediação das } \\
\text { professoras em sala de aula }\end{array}$ \\
\hline
\end{tabular}

Notam-se algumas convergências entre os resultados descritos pelos estudos revisados, como a unânime constatação da importância da língua de sinais para a criança surda. A despeito das semelhanças entre os resultados, as variações mais notáveis foram acerca dos eixos temáticos já mencionados, como educação, formação da identidade e escrita. De forma consistente com seu objetivo, o estudo de caso (artigo 4) apresentou resultados que se desejam passíveis de generalização para toda a comunidade surda com base em um caso clínico, enquanto o estudo de caso do artigo 7 evidenciou que seus resultados foram obtidos levando-se em consideração um único sujeito.

\section{DISCUSSÃO}

Com base na leitura dos artigos reunidos, percebe-se claramente que a surdez é uma realidade constituída de muitos contextos e, também, de muitas necessidades, que deveriam ser atendidas de modo simultâneo para que se possam obter resultados mais satisfatórios na melhoria da condição de vida da pessoa com surdez. No corpus do conhecimento revisado, a linguagem é admitida como principal mediadora para promover a satisfação das necessidades da pessoa. A fim de refinar melhor as pesquisas e conclusões acerca de tais contextos e necessidades, os autores dos artigos recuperados adotaram focos que, para enriquecimento da presente revisão, foram categorizados. Tais categorias serão apresentadas a seguir.

Embora o eixo temático da educação pareça ser o de maior importância, a categoria do simbolismo nas linguagens do surdo foi a que mais se destacou. Isso ocorreu devido à sua ampla influência no desenvolvimento da linguagem em si, pois esta tem símbolos e abstrações em sua base $^{5}$. Assim, ao ter como foco a gradual construção do simbólico, os artigos 8 e 9 mostram o que é preciso para tornar algo representativo para a criança surda - e esse é o princípio de sua capacidade para o desenvolvimento de gestos significativos (que originam a língua de sinais), depois, de representações pictográficas significativas (que possibilitam a escrita) e de signos orais significativos (que geram a compreensão da fala). 
0 sentido do gesto é sua interpretação, que, obviamente, está ancorada em cada interação social; ou seja, as interpretações são diferentes entre si e possuem diversas funções simbólicas ${ }^{9}$. Em virtude da interdependência de tais funções, de acordo com as autoras, o gesto serve de elo intermediário para a aquisição da linguagem oral, assim como da linguagem de sinais - sendo ainda mais significativo e compreensivo nessa segunda, por já ser um mecanismo visoespacial. Além disso, o referido estudo mostra que o grau de domínio da língua de sinais depende da estrutura de tais gestos.

Além de enfatizar a característica que propicia o status da língua de sinais como uma linguagem com suas respectivas regras, é clara a presença auxiliadora do gesto na fala dos ouvintes ${ }^{9}$. Logo, é muito lógica sua manifestação para o início da língua de sinais e, consequentemente, para a aquisição da fala oral e da escrita pela criança surda. Isso complementa o argumento de que "é a interpretação que transforma uma figuração em signo"10; e, igualmente, é essa interpretação que fornece à criança surda algo representativo, que ela compreende e, assim, passa a querer entender e a desejar fazer.

A pesquisa de Araújo e Lacerda ${ }^{10}$ avança ao delinear as diversas esferas simbólicas que constroem o conhecimento para a criança surda: o gesto, o desenho, a narrativa e a escrita. Baseando-se nas teorias de Vygotsky e Luria, as autoras postulam que a vivência da criança - isto é, sua experimentação da linguagem - é necessária, pois torna mais prazerosas as atividades de aquisição da noção da representatividade e o sentido de imagens, palavras, gestos e histórias. Em um primeiro instante, as autoras relatam o desinteresse das crianças surdas pela linguagem porque não a entendem: antes de as funções simbólicas se estabelecerem, elas não têm capacidade de narrar, contar, perguntar ou descrever com qualidade o que sabem ${ }^{10}$. Além disso, o simbolismo propicia a escrita, pois "as crianças vão da escrita pictográfica para uma escrita ideográfica, criando marcas simbólicas"10. Depois de apenas imitar os adultos, elas dominam a escrita e seus signos quando são capazes de interpretá-los. No eixo temático da escrita, encontram-se os artigos 2, 4 e 7. Todos admitem a necessidade da língua de sinais como primeira língua para que, posteriormente, se possa desenvolver a compreensão da língua portuguesa e, assim, a escrita. Porém, os estudos apresentam algumas divergências.

0 artigo 7 é o que mais se aproxima das questões levantadas pelos artigos 8 e 9 . Isso de deve, provavelmente, a ter sido escrito por três das autoras do artigo 9. Considera-se a necessidade de promover motivação, atividades prazerosas e oferta da língua de sinais para que se possa despertar interesse, vontade de realizar a escrita e, principalmente, de compartilhar experiências e narrações com os demais alunos $^{11}$. Indo ao encontro desses achados, o artigo 4 afirma a necessidade de se investir na transformação da mentalidade vigente, mudando o modo de o mundo se relacionar com o surdo, para que este mude e amplie seu modo de interação com o mundo ${ }^{12}$.

0 artigo 2, de abordagem psicanalítica, retrata o desenvolvimento da escrita como um processo que envolve diversos processos psíquicos inconscientes, como o recalcamento. Ao tratar escrita e leitura como processos similares ao da aquisição da linguagem, considera-as também como parte da estruturação subjetiva $^{13}$. 0 aspecto mais inovador desse estudo é a constatação explícita de que a criança pode "brincar" com a linguagem de sinais, tal como qualquer ouvinte que se diverte com a fala. Os trocadilhos da fala, por exemplo, podem ser representados em gestos, trocando sinais, "enganando" o interlocutor e ampliando sua possibilidade significante, juntamente com a escrita $^{13}$. Essa ideia abre a possibilidade da brincadeira de faz-de-conta - descrita por Piaget como frequente em crianças préescolares, na qual a imaginação para o desempenho de papéis é essencial e se faz por pensamento e simbolismo ${ }^{14}$. 
Tanto o artigo 2 quanto 07 são estudos de caso, o que ajuda a ter como foco a questão da escrita e permite recortes longitudinais, porém, enquanto o estudo 7 deixa claro que seus resultados referem-se ao sujeito analisado, o artigo 2 os generaliza para toda a população surda - o que, perante a heterogeneidade que caracteriza o universo da surdez, exposta por Gesueli ${ }^{15}$ e Sacks ${ }^{1}$, não é aconselhável.

As ideias até aqui expostas vinculamse, por sua vez, à formação da identidade surda. Os artigos 3 e 5 abordam tal eixo temático com base na língua de sinais, uma vez que esta, por ser mais natural ao surdo, permite-lhe se identificar com uma comunidade, constituir seu pensamento e, consequentemente, sua personalidade suas características próprias por meio do modo como significa a si próprio e o mundo ${ }^{15,16}$. Como ambos os artigos são teóricos e tratam da mesma especificidade, apresentam objetivos e resultados bastante semelhantes.

É preciso propiciar à criança condições para ser ativa e desenvolver a criatividade da qual é capaz, de modo que lhe seja necessário dominar uma língua que lhe possibilite a integração em seu meio, a fim de que o compreenda e signifique suas experiências, em vez de uma língua que a torne um ser apto para reproduzir o que, para ela, não terá nenhum significado comunicativo ${ }^{16}$.

Essa questão da atividade/passividade da criança surda ao desenvolver uma linguagem remete fortemente ao eixo temático família, no qual se insere apenas o artigo 6. Embora os demais estudos mencionem a família ouvinte do surdo, não a tomam como objeto específico de investigação. 0 artigo 6 tem como foco as mães. Segundo Silva, Pereira e Zanolli17, a concepção que as mães têm sobre a surdez influencia a modalidade da linguagem usada pelos filhos surdos. Em sua pesquisa, as mães que consideram a surdez como doença procuram incentivar a fala oral e o aprendizado da língua portuguesa nas crianças surdas, enquanto as que a veem apenas como diferença julgam importante a língua de sinais.

Como os outros artigos afirmam, o tipo de linguagem usado pela criança interfere no processo de constituição de sua identidade e subjetividade, além do fato de que a exigência demasiada da língua portuguesa em detrimento da de sinais pode prejudicar as funções simbólicas da linguagem, que são a base para o desenvolvimento dessas crianças. As famílias normalmente exigem e usam mais a língua portuguesa pela vantagem do status que ela proporciona na majoritária comunidade ouvinte, além de ser mais fácil para a convivência com os familiares ouvintes ${ }^{13,17}$. É necessário disseminar informações acerca da surdez, de esclarecer o assunto junto à comunidade e de desmistificar tabus que reforçam estereótipos sociais ${ }^{17}$.

As mães da pesquisa em questão mostraram-se satisfeitas com as orientações que receberam do centro no qual o estudo empírico foi realizado, e admitiram não possuir conhecimentos além dos proporcionados pelos profissionais desse centro ${ }^{17}$. Muitos professores, mencionados nos demais artigos revisados, também admitiram não ter base suficiente para educar crianças surdas. Isso não ocorre sempre por falta de competência ou por preconceito, mas também por falta de conhecimento sobre a condição da surdez e a importância do desenvolvimento da linguagem quando tem o suporte de uma pessoa mais experiente, como os pais, os professores ou mesmo amigos. Assim, a educação bilíngue ou a de sinais não é prejudicada por ser promovida em uma escola normal para crianças ouvintes, pois estas podem auxiliar as crianças surdas apenas pelo convívio, enquanto, em uma escola só de surdos, eles podem ficar restritos em alguns aspectos. É claro que, nesse aspecto, é importante o uso dos sinais e, se possível, de professores ou instrutores especializados, para que a criança surda não fique prejudicada em aulas com alunos ouvintes ${ }^{10}$. 
Todos os estudos remetem à questão do simbolismo da linguagem e, inclusive, das demais esferas simbólicas, mas poucos o abordam. Isso pode dificultar a elucidação de especificidades próprias do contexto da surdez, principalmente das aqui categorizadas como identidade, escrita e educação. Além disso, embora discorram sobre a linguagem, poucos analisam seu desenvolvimento - e, nesse aspecto, a função simbólica é essencial, de modo que o artigo 8 se mostrou o mais completo, sem se propor a abordar o desenvolvimento da linguagem.

Aliás, há uma ressalva nesse ponto. Embora não seja errado empregar o termo "aquisição" da linguagem como sinônimo de "desenvolvimento" desta, o primeiro sugere uma ideia de passividade, que esta revisão se propõe a questionar, com base nos artigos considerados. "Aquisição" refere-se a "adquirir"; é como se a linguagem fosse algo pronto, externo ao indivíduo e passível de obtenção. Essa noção tem que ser problematizada porque pode agravar, mesmo que involuntariamente, o preconceito social existente em relação à surdez. Já o conceito de "desenvolvimento" abarca uma ideia de evolução, de "criação" gradual, segundo a qual o indivíduo pode usar ativamente suas habilidades e novas experiências para a melhoria de sua própria condição. Se analisadas sob a perspectiva de Vygotsky $^{2}$, para quem as palavras influenciam o pensamento, tais noções poderiam interferir na concepção que se tem acerca da surdez, sendo preferível, em todo o caso, "desenvolvimento da linguagem".

Tal desenvolvimento, assim, é o ponto primordial da formação do surdo. Ele amplia sua possibilidade significante, de pensamento e de abstração, inerente apenas ao ser humano ${ }^{5}$; portanto, não se mostra tão exagerada (quanto aparenta à primeira vista) a afirmação de que permitir uma linguagem - qualquer que seja - ao surdo é devolver-lhe a condição de humanidade ${ }^{13}$, ou seja, é fornecer-lhe características tipicamente humanas as quais sua condição peculiar de desenvolvimento dificulta alcançar.

\section{CONCLUSÃO}

O universo da surdez, principalmente no que concerne ao desenvolvimento da linguagem, do pensamento e das descobertas da criança surda, constitui uma área de conhecimento ampla e fascinante. Isso ocorre, talvez, por ser ainda um mundo amplamente desconhecido da população ouvinte, tornando-se, por isso, exótico, estranho, novo e complicado. Portanto, é necessário promover maior contato entre as comunidades surda e ouvinte, a fim de que elas se descubram e se enriqueçam mutuamente.

A presente revisão demonstra a necessidade de se desenvolver mais estudos brasileiros acerca do contexto da surdez e de sua relação com o desenvolvimento da linguagem e a questão simbólica. Tais informações são úteis para o surdo conhecer suas condições e possibilidades, mas a comunidade ouvinte deveria ser o principal foco, ao contrário do que se pensa, pois dela partem os preconceitos e as ações responsáveis por alimentar a discriminação que cerca a situação do surdo. 0 presente estudo evidencia que ainda existem muitas dificuldades de acesso à informação sobre a surdez. Só o conhecimento científico poderá minorar as limitações que reforçam as barreiras sociais que sustentam mundos excludentes para surdos e ouvintes.

A maior disseminação pública sobre o tema poderia produzir impactos semelhantes nas pessoas alheias à surdez, aprimorando suas concepções. Atuar sobre a modificação dessas crenças é importante, como mostram alguns dos estudos revisados, porque elas influenciam nas linguagens utilizadas pelos surdos.

\section{REFERÊNCIAS}

1. Sacks O. Vendo vozes: uma viagem ao mundo dos surdos. Mota LT, tradutor. São Paulo: Companhia das Letras; 2010.

2. Vygotsky LS. Pensamento e linguagem. Camargo JL, tradutor. São Paulo: Martins Fontes; 2008. 
3. Espote R, Serralha CA, Scorsolini-Comin F. Inclusão de surdos em ambiente escolar: revisão integrativa da literatura científica. Psico USF. 2013; 18(1):77-88.

4. Fávero MH, Pimenta ML. Pensamento e linguagem: a língua de sinais na resolução de problemas. Psicol. Reflex. Crít. 2006; 19(2):225-36.

5. Devlin KJ. O gene da matemática. Rego SM, tradutor. Rio de Janeiro: Record; 2006.

6. Trask RL. Dicionário de linguagem e lingüística. Ilari R, tradutor. São Paulo: Contexto; 2004.

7. Sacks O. Apresentação à primeira edição do DeitLibras. In: Capovilla FC, Raphael WD, Mauricio AC. Novo Deit-Libras: dicionário enciclopédico ilustrado trilíngue da língua brasileira de sinais (Libras), baseado em linguística e neurociências cognitivas. São Paulo: EDUSP; 2009.

8. Creswell JW. Projeto de pesquisa: métodos qualitativo, quantitativo e misto. Lopes M, tradutor. Porto Alegre: Artmed; 2010. Revisão da literatura; p. 49-75.

9. Santana AP, Guarinello AC, Berberian AP, Massi G. 0 estatuto simbólico dos gestos no contexto da surdez. Psicol. Estud. 2008; 13(2):297-306.

10. Araújo CCM, Lacerda CBF. Esferas de atividade simbólica e a construção de conhecimento pela criança surda. Rev. Bras. Educ. Espec. 2008; 14(3):427-46.

11. Guarinello AC, Massi G, Berberian AP. Surdez e linguagem escrita: um estudo de caso. Rev. Bras. Educ. Espec. 2007; 13(2):205-18.

12. Peixoto RC. Algumas considerações sobre a interface entre a língua brasileira de sinais (LIBRAS) e a língua portuguesa na construção inicial da escrita pela criança surda. Cad CEDES. 2006; 26(69):205-29.

13. Carvalho CD, Rafaeli YM. A língua de sinais e a escrita: possibilidades de se dizer para o surdo. Estilos Clín. 2003; 8(14):60-7.

14. Bee H. A criança em desenvolvimento. Veronese MAV, tradutor. Porto Alegre: Artmed; 2003.

15. Gesueli ZM. Lingua(gem) e identidade: a surdez em questão. Educ. Soc. 2006; 27(94):277-92.

Dizeu LCTB, Caporali SA. A língua de sinais constituindo o surdo como sujeito. Educ. Soc. 2005; 26(91):583-97.

16. Silva ABP, Pereira MCC, Zanolli ML. Mães ouvintes com filhos surdos: concepção de surdez e escolha da modalidade de linguagem. Psicol. Teor. Pesq. 2007; 23(3):279-86.

17. Rodriguero CRB. O desenvolvimento da linguagem e a educação do surdo. Psicol. Estud. 2000; 5(2):99-116.

18. Bomfim RO, Souza APR. Surdez, mediação e linguagem na escola. Psicol. USP. 2010; 21(2):417-37.

\section{CONTRIBUIÇÕES}

Nathália Fernandes Minaré desenhou o estudo, realizou a coleta e análise dos artigos, bem como a redação final;

Fabio Scorsolini-Comin orientou o desenvolvimento da pesquisa e colaborou com a redação, formatação e revisão do texto;

Manoel Antônio dos Santos colaborou com a análise dos artigos selecionados e participou da revisão do texto. 